\title{
Assessment of market milk adulteration in Tiruchirapalli city of Tamil Nadu
}

\author{
G. Rajarajan
}

Received: 13 December 2020 / Accepted: 01 April 2021 / Published online: 27 July 2021

(c) Indian Dairy Association (India) 2021

\begin{abstract}
A study was conducted to analyze the market milk samples sold in Tiruchirapalli city of Tamil Nadu for the presence of adulterants.A total of 110 milk samples, 10 from the organized brands, 50 from local vendors and 50 from tea and coffee shops were collected.The present study revealed the presence of starch in 02 milk samples $(1.82 \%)$ and that to from organized brands were detected. Further, the presence of neutralizers, detergents and sodium chloride were found in 36 samples(32.73\%), 21 milk samples $(19.09 \%)$ and 33 milk samples (30\%)respectively.The skimmed milk powder was detected in all the ten organized brands. The milk samples obtained from local vendors, tea and coffee shop were negative for skimmed milk powder. The study also revealed the presence of sugar in 45 milk samples $(40.91 \%)$, hydrogen peroxide in 03 samples $(2.73 \%)$ and pond water/nitrate in 20 milk samples (18.18\%) respectively. In addition, the study revealed that none of the samples collected were found positive for the presence of alizarin, formalin, urea, glucose/dextrose, cellulose, maltodextrin, protein and boric acid.
\end{abstract}

Keywords: Adulterants, Detection methods, Market milk, Tiruchirapalli city

\section{Introduction}

India has emerged as the largest milk producer and consumer in the world with an annual production of more than 187.7 million

G Rajarajan ( $\square)$

Department of Livestock Products Technology,

Veterinary College and Research Institute,

Orathanadu - 614 625-Thanjavur

Tamil Nadu Veterinary Animal Sciences University, Tamil Nadu, India

Email: rajarajanvet@gmail.com tones, giving a per capita availability of 394 gm per day (NDDB, 2019). India's milk production today accounts for $22.3 \%$ of the total world output and $40 \%$ of the Asia's total production.

Milk in its natural form has high food value. It supplies nutrients like proteins, fat, carbohydrates, vitamins and minerals in moderate amounts in an easily digestible form. Nutritional values and other health benefits have made milk and dairy products to be extensively consumed by large segments of the population during all stages of development and life including childhood, adolescence, pregnancy and the elderly. Adulteration can be defined as the inclusion in foods of constituents whose presence is prohibited by regulation, custom and practice or "making impure by adding inferior, alien or less desirable materials or elements"(Sonal et al. 2013).

The addition of adulterants to food to increase attractiveness and value is often referred to as "economic-adulteration".Milk may be adulterated on purpose and mostly motivated by economic greed, or accidentally during production or processing. The driving force behind most adulteration is to maximize revenues by using (partially) either a cheap ingredient as a substitute for a more expensive one, or (partially) removing the valued component in the hope that the altered product is undetected by the final user. Adulteration is an act of intentionally debasing the quality of food offered for sale either by admixture or substitution of inferior substances or by the removal of some valuable ingredients as per Food and Drug Administration (1995).

In the National Survey on Milk adulteration (2011) conducted by the Food Safety and Standards of Authority of India (FSSAI) to ascertain the quality of milk throughout the country, $68.4 \%$ samples were found to be non-conforming to Food Safety and Standards Regulations, 2011. The FSSAI latest report of October 2019 on National Milk Safety and Quality Survey which was conducted during 2018 reveals that milk in India is largely safe, even though quality issue persists. The survey found that less than $10 \%$ of milk samples had contaminants coming mainly from feeds and improper farming practices (FSSAI, 2019). 
The proposed study on adulteration of milk will bring about more awareness to the general public about the malpractices or negligence in milk production. Added to that it will establish its importance in formulating future food safety measures thus will address the health concern of the Tiruchirapalli city in particular and the state of Tamil Nadu in general with the following objectives.Collection of milk samples from organized brands, local vendors, tea and coffee shops from different areas in Tiruchirapalli city of Tamil Nadu. The collected milk samples were tested for the presence of different adulterants, viz., alizarin, formalin, urea, starch, neutralizers, detergent, sodium chloride, skim milk powder, sugar, glucose, hydrogen peroxide, cellulose, maltose, ammonium sulphate, protein, boric acid, pond water / nitrate.

\section{Materials and Methods}

\section{Collection of milk samples}

Tiruchirapalli city is located at the centre of Tamil Nadu, gets most of the milk supply from the surrounding villages, private dairies and cooperative milk union. The city comprise of four zones containing 65 wards. The market milk samples were collected randomly from all the four zones. A total of 110 milk samples, 10 from the organized brands, 50 from local vendors and 50 from tea and coffee shops were collected aseptically and were transported in an icebox at a suitable temperature range $\left(0-4^{\circ} \mathrm{C}\right)$ to the laboratory within two hours. The collected milk samples were analyzed in Veterinary University Training and Research Centre, Tiruchirapalli.

\section{Adul-teration testing using milk kit}

The kit for adulteration testing of milk was obtained from Himedia, Mumbai. The kit was designed for the detection of common seventeen milk adulterants in the milk sample (Bhanu et al. 2014).It was available in two parts, the Part A of the kit- K088A consisting of reagents for detection of 11 adulterants namely Alizarin, Formalin, Urea, Starch, Neutralizers, Detergents, Sodium chloride, Skim Milk powder, Sugars, Glucose/Dextrose and Hydrogen Peroxide. The Part B of the kit-K088B consisting of reagents for detection of 6 adulterants namely Cellulose, Maltodextrin / Maltose, Ammonium Sulphate, Proteins, Boric Acid and Pond Water/Nitrate. The kit was utilized for testing 50 samples each and was simple to carryout tests at field level and results could have been obtained rapidly. By observing colour changes we could decide the presence or absence of different adulterants (Table 1 and Fig. 1).

\section{Results and Discussion}

The market milk samples collected from organised brands, local vendors, tea and coffee shops from Tiruchirapalli city of Tamil Nadu were analysed for seventeen different adulterants and the results are presented in Table 2

Table 1 Detection of adulterants in market milk

\begin{tabular}{|c|c|c|c|}
\hline S. No. & Adulterant & Presence & Absence \\
\hline \multirow[t]{2}{*}{$\overline{1 .}$} & Alizarin & Acidic-Reddish orange- $\mathrm{pH} 5.8$ & Normal milk- Red-pH 6.8 \\
\hline & (Acidity and Heat stability) & Alkaline- Reddish violet- $\mathrm{pH} 7.8$ & \\
\hline 2. & Formalin & Purple / Violet colour ring & Brownish yellow coloured ring \\
\hline 3. & Urea & Yellow colour & Off white to slight yellow colour \\
\hline 4. & Starch & Blue colour & Off white to cream colour \\
\hline 5. & $\begin{array}{l}\text { Neutralizers (Sodium } \\
\text { bicarbonate, Sodium } \\
\text { carbonate, Sodium hydroxide } \\
\text { and Calcium hydroxide) }\end{array}$ & Reddish pink & Light orange \\
\hline 6. & $\begin{array}{l}\text { Detergents (Washing } \\
\text { powder, Shampoo) }\end{array}$ & Blue Slate Grey (Shampoo) & Grayish blue \\
\hline 7. & Sodium chloride & Yellow & Brick red \\
\hline 8. & Skim milk powder & Bluish & Greenish \\
\hline 12. & Cellulose & Moss green & Yellow \\
\hline 13. & Maltodextrin/Maltose & Brown & Golden yellow \\
\hline \multirow[t]{2}{*}{14.} & Ammonium sulphate & Teal blue (Cons d" $0.5 \%$ ) & Wheat colour \\
\hline & & Alabaster (Cons $>0.5 \%)$ & \\
\hline 15. & Proteins & Pink & Colourless \\
\hline 16. & Boric acid & Reddish orange & Turmeric yellow \\
\hline 17. & Pond water / Nitrate & Pink magneta & White to off white \\
\hline
\end{tabular}




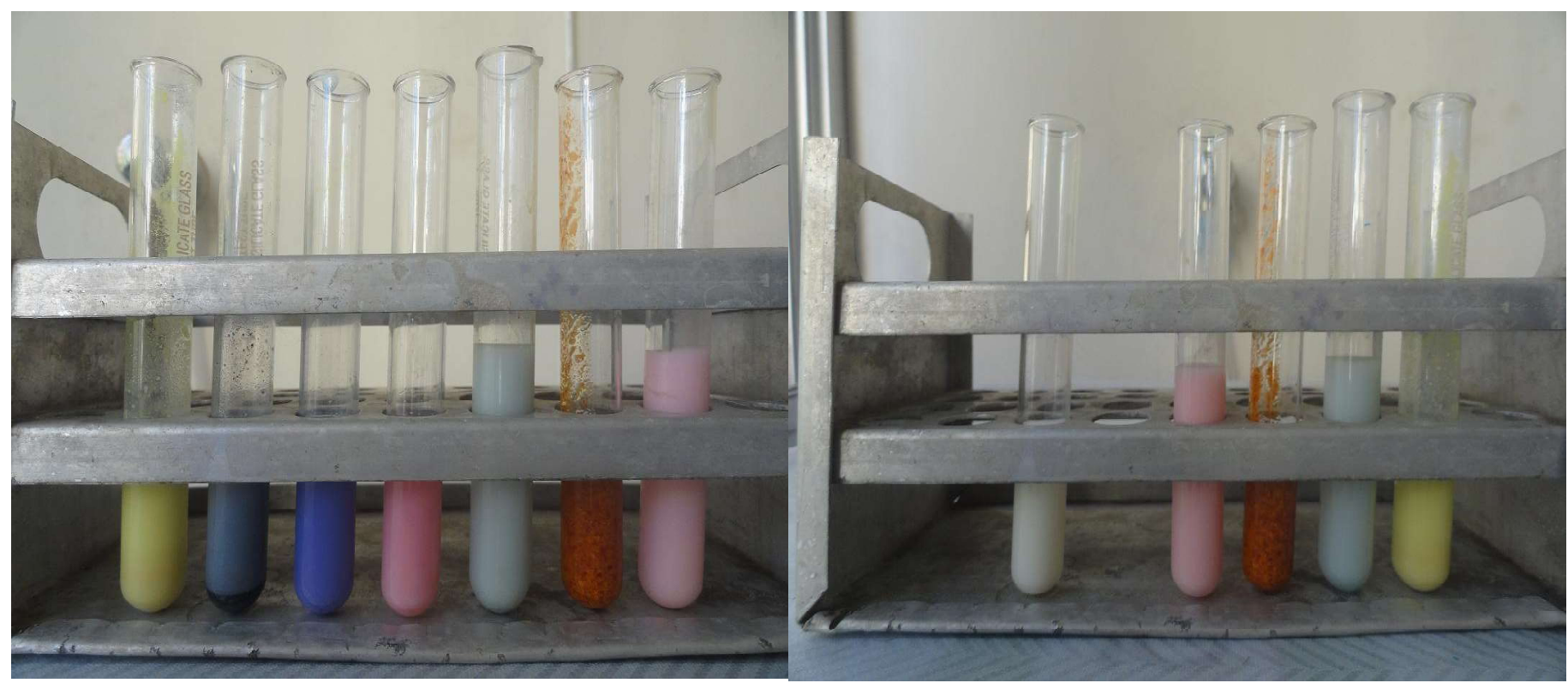

Fig. 1 Test results of milk samples for urea,starch, neutralizer, detergents, sodium chloride, sugar, cellulose and nitrate

\section{Alizarin (acidity and heat stability)}

None of the milk sample was found positive for Alizarin. Acidity is a measure of freshness and bacterial activity in milk. Among 110 milk samples tested, 71 samples had $\mathrm{pH}$ in normal range, 36 had acidic side and 03 in alkaline side. Most of the milk samples collected from the local milk vendors, tea and coffee shops showed acidic $\mathrm{pH}$. Lack of refrigeration leads to microbial fermentation of milk sugar might be the reason for higher acidity in theses samples.

\section{Formalin}

Addition of formalin even at low concentration in milk inhibit proliferation of bacteria and help in keeping quality of milk for longer period (Bansal and Singhal, 1991). None of the milk sample was detected for presence of formalin in present study; indicate the lack of awareness of milk sellers about the use formalin for increasing keeping quality of milk. In contrast, Arora et al. (2004), Sanjeevani et al. (2011) and Abbas et al. (2013) reported the presence of formalin in milk samples at the level of $0.4 \%, 12 \%$ and $28.33 \%$ in market milk samples tested in Delhi, Nanded town in Maharashtra and Peshawar in Pakistan respectively.

\section{Urea}

Urea is usually added to milk to elevate nitrogen content and mimic a high protein concentration. Addition of water in milk leads to disappearance of foamy appearance of milk. Urea is being used to restore the milky appearance. Urea is an end product of nitrogen metabolism and a normal constituent of milk. It is usually found between 180 and 400 ppm and constitutes about $55 \%$ of the non-protein nitrogen compounds (Paradkar et al. 2000). The cut-off concentration for urea in milk is normally set at $700 \mathrm{ppm}$ (Nikoleli et al. 2010). The presence of urea in milk above this limit could cause severe health problems for humans such as indigestion, acidity, ulcers, etc. (Trivedi et al. 2009). The present study revealed that none of the milk sample was found positive for urea. Abbas et al. (2013) reported that none of the milk sample collected from Peshawar district, Pakistan was positive for urea. In contrast, detection of urea adulteration reported by Nirwal et al. (2013) in different regions of Dehradun in Uttarakhand and Deepti (2014) in Akola city of Maharashtra state.

\section{Starch}

Starch is usually added to synthetic milk to improve its appearance, mainly viscosity, to compensate the effect of water adulteration. Starch improves the value of total solids up to the level acceptable by the consumers (El-Loly et al. 2013). Among 110 milk samples tested, two samples $(1.82 \%)$ were positive for starch. Ahmad (2009) collected three hundred milk samples from three different localities in Sudan and observed for adulteration with starch that $35.5 \%$ of samples were found adulterated with starch. Abbas et al. (2013) detected 26.66\% of milk samplesadulterated with starch in Peshawar district, Pakistan. However Islam et al. (2013); Nirwal et al. (2013), El-Loly (2013), Hossain (2013) and Deepti (2014) reported that none of the milk sample was positive for starch.

\section{Neutralizers}

Neutralizers are adulterated with milk to mask the acidity and to improve the apparent quality. There were 36 samples $(32.73 \%)$ out of 110 were found to be positive for neutralizers in the present study. Bhanu et al. (2014) reported presence of neutralizers in 15 


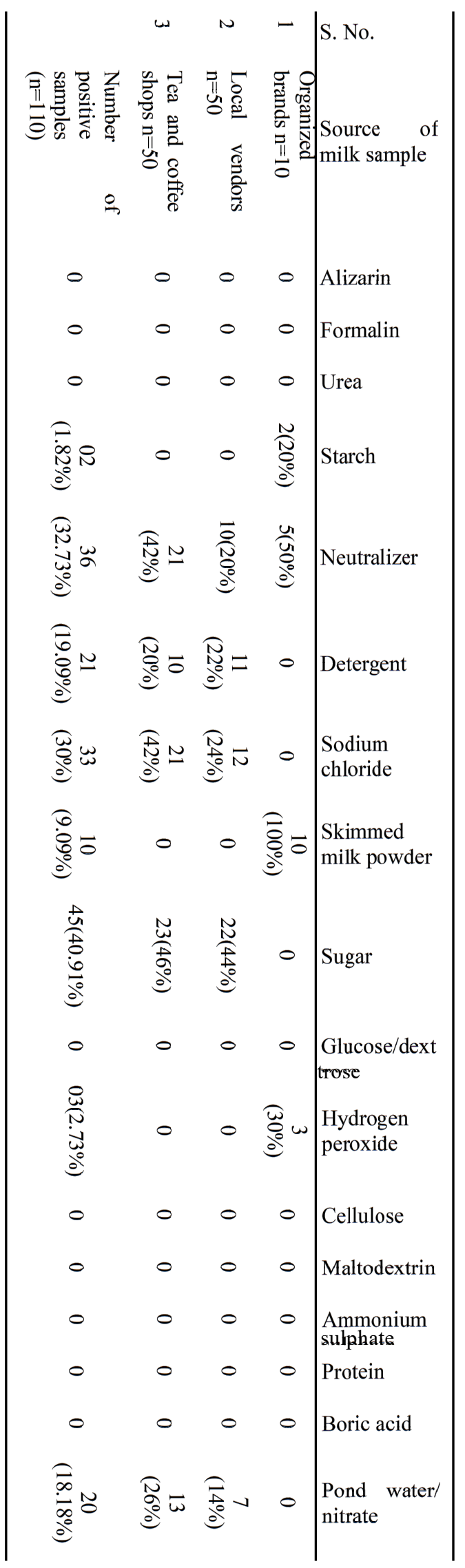

\% $\%$ of market milk sold in Chennai. Deepti (2014) reported presence of neutralizers in one out of ten milk samples of different company pouch in Akola city of Maharashtra state.

\section{Detergents}

Detergents are either deliberately added to improve the appearance of milk or it may get in to milk due to improper rinsing of milk utensils after detergent wash. Out of 110 milk samples twenty-one (19.09\%) was positive for detergent test in this study. As per National Survey on Milk Adulteration 2011, 8.4 \% of milk samples collected throughout India was found adulterated with detergent (FSSAI Report, 2011). Similarly, Nirwal et al. (2013) reported positive results for detergent in milk quality analysis in Dehradun. In contrast, Abbas et al. (2013) reported that none of the milk sample tested was positive for detergent in Peshawar district, Pakistan.

\section{Sodium chloride}

Sodium chloride or salt are added to milk to mask higher water content. Total of 33 milk samples $(30 \%)$ out of 110 tested were positive for sodium chloride. Similarly, Arora et al. (2004) observed that in all the collected milk samples from organized and unorganized sector $0.6 \%$ samples were positive for sodium chloride detection test. Abbas et al. (2013) reported $16.66 \%$ positive results for sodium chloride test in milk samples collected from Peshawar district, Pakistan. Deepti (2014) reported very high positive results for sodium chloride in five out of ten milk samples tested in Akola city. Nirwal et al. (2013) reported 51\% positive samples for sodium chloride in Dehradun.

\section{Skim milk powder}

Skim milk powder is added to milk to improve the solid not fat content of milk and/or mask the added water.In present study 10 samples $(9.09 \%)$ out of 110 were positive for skim milk powder test. As per National Survey on Milk Adulteration 2011, there were 548 milk samples out of 1791 ie. $44.69 \%$ positive for skim milk powder adulteration (FSSAI Report, 2011). Similarly, Deepti (2014) reported $20 \%$ positive result for skim milk powder adulteration. Nirwal et al. (2013) reported that $58 \%$ of milk they tested was positive for skim milk powder adulteration. But in true sense, presence of skim milk powder should not be considered as an adulterant as it is produced from milk only.

\section{Sugar}

Sugar usually added to improve the solid not fat content of milk and/or to mask the added water. There were 45 milk samples $(40.91 \%)$ out of 110 collected in this study were found to be positive for added sugar. Abbas et al. (2013) reported 18.33\% sugar adulteration in milk samples collected in Peshawar district, Pakistan. Lateef et al. (2009) reported very high $i$.e. $93.33 \%$ cane sugar adulteration in milk. Deepti (2014) detected 3 milk samples 
with sugar out of 10 samples. Nirwal et al. (2013) observed $20 \%$ milk adulteration with sugar during summer, $12 \%$ in rainy and 3 $\%$ in winter season.

\section{Glucose / Dextrose}

Glucose or Dextrose is added to milk to enhance Solid Not Fat (SNF) portion of milk. The presence study revealed that none of the milk sample was found positive for presence of glucose or dextrose. In contrast to this, National Survey on Milk Adulteration (2011) revealed that 477 milk samples out of 1791 were adulterated with glucose (Anonymous, 2011). In an assessment of adulteration in skimmed milk samples of Akola city, out of 8 milk samples there were 3 samples with glucose adulteration (Deepti, 2014). In a milk quality analysis in Dehradun conducted by Nirwal et al. (2013), $80 \%$ of milk samples were found to be adulterated with glucose.

\section{Hydrogen peroxide}

To increase the shelf life of raw milk hydrogen peroxide is added. This unethical activity is usually adopted in summer season when the environment temperature is very high, to prevent the spoilage milk during transport (Tipu et al. 2007). The present study revealed that 03 milk samples $(2.73 \%)$ out of 110 were found to be adulterated with hydrogen peroxide. There were $23.5 \%$ pasteurized milk samples and $5.58 \%$ raw milk samples foundpositive for hydrogen peroxide. (Wangala and Wafula, 2007). In contrast, none of the milk sample was found positive for hydrogen peroxide reported by Mishra et al. (1977), Patel (1979), Karpude et al. (1987), Rao et al. (2002), Abbas et al. (2013), Deepti (2014). Reason for the absence of Hydrogen peroxide adulteration was may be that it is not easily and cheaply available in the open market.

\section{Cellulose}

The present study revealed the absence of cellulose in all the 110 milk samples analyzed. Similarly, Deepti (2014) also reported that, none of the skim milk samples analyzed for adulteration from Akola city was positive for cellulose test. Absence of cellulose in any of the milk samples could be due to unawareness of cellulose among milk vendors.

\section{Maltodextrin/Maltose}

Out of 110 milk samples tested, no one was found positive for Maltodextrin / maltose. This was in agreement with Deepti (2014). The reason may be that Maltodextrin / maltose is not available cheaply in the open market.

\section{Ammonium Sulphate}

The milk vendors may add ammonium sulphate to milk in order to increases the lactometer reading by maintaining the density of milk. None of the milk sample in this experiment was adulterated with Ammonium Sulphate.

\section{Proteins}

The presence of protein milk samples vary between 3.0 and 4.1 $\%$. The present study revealed that none of the milk sample was deviated from the normal range which in turn ruled out the addition of extraneous protein in the tested milk samples. In contrast, Deepti (2014) reported three skim milk samples were found above normal range of protein and none below the normal range in Akola city of Maharashtra state.

\section{Boric acid}

Out of 110 milk samples analyzed, Boric acid was not detected in any of the milk samples in this study. The result was in agreement with that of Nirwal et al. (2013) and Deepti (2014). In contrast, Abbas et al. (2013) reported $11.67 \%$ of milk samples adulterated with Boric acid in Peshawar in Pakistan.

\section{Pond water / Nitrate}

Twenty milk samples (18.18\%) out of 110 were found positive for pond water / nitrate in this study. This may be due to addition of raw water in milk samples to increase the volume by local vendors, tea and coffee shops. Deepti (2014) reported presence of one sample with pond water / nitrate out of ten samples tested in Akola city of Maharashtra state.

\section{Conclusions}

Adulteration is an act of intentionally debasing the quality of food offered for sale either by admixture or substitution of inferior substances or by the removal of some valuable ingredients. The driving force behind most adulteration is to maximize revenues by using (partially) either a cheap ingredient as a substitute for a more expensive one, or (partially) removing the valued component in the hope that the altered product is undetected by the final user. The market milk samples of Tiruchirapalli city in Tamil Nadu were analyzed for the presence of adulterants. The study revealed that nearly $41 \%$ of market milk samples were adulterated with any one of the adulterants tested. The adulteration was found to be more in milk samples collected from tea and coffee shops than those from organised brands. The present study on adulteration of market milk will bring about more awareness to the general public about the malpractices or negligence in milk production, processing and distribution to public. Added to that it will establish its importance in formulating future food safety measures which in turn address the health concern of the Tiruchirapalli city in particular and the state of Tamil Nadu in general.

\section{Acknowledgements}


The support extended by the Director of Extension Education of Tamil Nadu Veterinary and Animal Sciences University (TANUVAS) is duly acknowledged.

\section{References}

20th Livestock Census Report (2019) Department of Animal Husbandry and Dairying. Ministry

of Fisheries, Animal Husbandry and Dairying. Government of India. Krishi Bhawan, New Delhi, India.

Abbas MN, Khattak B, Sajid A, Ul Islam T, Jamal Q, Munir S (2013) Biochemical and bacteriological analysis of milk samples collected from district Peshawar. Int J Pharm Sci Rev Res.21: 221-26

Ahmad A (2009) Milk adulteration by adding water and starch at Khartoum State. Pak J Nutr8: 439-440

Arora S, Sharma V, Motiram D, Kishore K (2004) Status of milk adulteration in some states of North India. Ind J Dairy Sci57:65-67

Bansal A, Singhal OP (1991) Preservation of milk samples with formalinEffect on Acidity. Ind J Dairy Sci44:573

Bhanu RV, Gunaseelan L, Pawar GR, GiriT (2014) Assessment of adulteration and microbial quality of market milk in Chennai. Indian Vet J 91: 50-51

Deepti T (2014) Assessment of adulteration found in skimmed milk samples collected from Akola City. Ind J Res 3: 171-73

El-loly MM, Mansour AA, Ahmed RO (2013) Evaluation of raw milk for common commercial additives and heat treatments. Int J Food Safe 15: $7-11$

FSSAI (2019) Food Safety and Standards Authority of India Survey: Your Milk is Largely Safe. Press release on National Milk Safety and Quality Survey 2018, New Delhi, pp 1-7

Hossain M, Bellal A, Dev SR (2013) Physiochemical characteristics of various raw milk samples in a selected dairy plant of Bangladesh. Int J Engg App Sci 1: 91-96

Karpude AA, Rathi SD, Joglekar NV, Ingle UM (1987) Adulterated milk sold in Parbhani town. Asian J Dai Res 6: 83-86

Lateef M, Faraz A, Mustafa MI, Akthar P, Bashir MK (2009) Detection of adulterants and chemical composition of milk supplied to canteens of various hospitals in Faisalabad city. Pak J Zool 9: 139-142
Mishra M, Dehury M, Nayak JB (1977) Adulteration of market milk at Bhubaneswar. Ind J Vet Sci 12:378-380

National Dairy Development Board (2019) Department of Animal Husbandry, Dairying and Fisheries, Ministry of Fisheries, Animal Husbandry and Dairying, Government of India.

Nikoleli GN, Nikolelis DP, Methenitis C (2010) Construction of a simple optical sensor based on air stable lipid film with incorporated urease for the rapid detection of urea in milk. Anal Chim Acta 675: 58-63

Nirwal S, Pant R, Rai N (2013) Analysis of milk quality, adulteration and mastitis in milk samples collected from different regions of Dehradun. Int J Pharm Technol 5: 359-64

Paradkar MM, Singhal RS, Kulkarni PR (2000) An approach to the detection of synthetic milk in dairy milk: 1 . Detection of urea. Int J Dairy Technol 53: 87-91

Patel RK (1979) A study on the quality of milk collected at different collection centre. Dairy guide 1: 27-29

Rao LV, Ranganadhan M, Rao VR (2002) Quality of milk and milk products marketed in Hyderabad city. Indian J Dairy Sci 55: 338

Sanjeevani B, Wadekar BR, Chavan R, Menkudale GV (2011) Survey on adulteration of the milk received from government milk scheme in Nanded town. Interlink Research Analysis 1: 4-9

Sonal G, Suman K, Neelima B and Kameshwar SYVR (2013) Screening of Adulterants in the Milk and Dairy Products of Delhi Region - A case study. Int J Pharm Technol 4: 4889-4897

Tipu MS, AltafI, Ashfaq M, Siddique (2007) Monitoring of chemical adulterants and hygienic status of market milk. Handbook published by Quality control Laboratory, University of Veterinary and Animal Science, Lahore, Pakistan, pp 7

Trivedi UB, Lakhminarayana D, KothariL, Patel G, Kapse N, Makhija K, Patel B, Panchal J (2009) Potentiometric biosensor for urea determination in milk. Sens Actuators B Chem140: 260-266

Wangala K, Wafula G (2007) Evaluation of Microbiological Quality and safety of milk marketed in Nairobi and Environs. Jomo Kenyatta University of Agriculture and Technology, Kenya 